\title{
ТЕОРИИ СПРАВЕДЛИВОСТИ И ПРОБЛЕМА РАЦИОНАЛЬНОГО ОБОСНОВАНИЯ МОРАЛИ
}

\section{Н.В. Шрамко}

После краха Советского Союза, с его системой государственного планирования, многочисленные оптимистично настроенные «эксперты» дружно убеждали нас в том, что современная экономическая и социологическая мысль Запада давно располагает всеми необходимыми рецептами, применение которых в странах постсоветского пространства способно в кратчайшие сроки привести к наивысшему уровню производства материальных и духовных благ, бурному росту «богатства народов», главным (и неиссякаемым) источником которого должен явиться свободный рынок. Эффективность рыночного уклада экономики выводилась ими из свободного выбора разумных индивидов, что получило соответствующее закрепление в подходящем категориальном аппарате, использующем такие понятия как «свобода личности», «индивидуальная рациональность», «социальная справедливость», «общественный договор» и т.п.

Впрочем, совокупность теоретических проблем, а зачастую и предлагаемые решения, затрагивающие принципиально важные для современного социума вопросы основ глубинной идеологии общественного существования на поверку оказались не такими уж новыми для бывших воспитанников теории научного коммунизма и исторического материализма. Хотя, само погружение в ситуацию свободного рынка и неоходимость, или даже принудительность, «рационального» выбора в условиях, порой очень далеких от рациональных, явилось совершенно новым ощущением.

В то же время, в последние несколько десятилетий многие западные философы активно включились в разработку данной проблематики и, освоив экономическую терминологию, по-новому попытались решить старые традиционные вопросы практической философии, в частности, этики. Ключевой идеей здесь явилось представление о том, что фактор «рациональности» оказывается на поверку феноменом, требующим дополни-

Актуальні проблеми духовності

(Відп. ред.: Я.В. Шрамко)

Кривий Ріг (2005), 332-337 
тельных (сопутствующих) параметров в виде этических концепций, без которых рационально функционирующее, а значит и справедливо устроенное, общество необъяснимо.

Одна из таких получивших большую известность попыток построить теорию социальной справедливости была предпринята Дж. Ролзом, который опубликовал в 1971 году книгу под названием «Теория справедливости» (см. [3] и [4]). Полемика, вызванная этой книгой, в которой приняли участие такие ведущие теоретики современного либерализма как $\Phi$. Хайек, С.Кууказас, Р.Нозик, представители современного коммюнитаризма А. Макинтаир, М. Сандел, М. Валзер, Ч. Тайлор, стала поистине классической и вызвала, в свою очередь, целый ряд публикация, в том числе монографий, посвященных самой этой полемике (см., напр. [2], [6]).

В качестве исходной позиции при обсуждении данной проблематики рассмотрим логический ход, используемый Ролзом, который задействует категорию «общественного договора» как некую теоретическую модель, однако перенесенную на более высокий, чем это имело место в трудах мыслителей Нового времени, уровень абстракции. По его мнению, необходимо подвергнуть анализу ситуацию, когда «все участники социального взаимодействия одним временным актом совместно выбирают те принципы, которые определяют основные права, обязанности и распределение социальных благ» $[4$, с. 236]. В этой гипотетической ситуации все участники с неизбежностью должны были бы выбрать в качестве главных постулатов, определяющих уклад всех сторон социально-политической жизни, два основных принципах: принцип равенства и принцип «неравенства» или «различия». Первый принцип означает, что каждый человек имеет право на обладание максимальной политической свободой, совместимой с аналогичной свободой для всех остальных. Второй же принцип гарантирует при сущестсвующем неравенстве (социальном и экономическом) компенсацию благ наименее преуспевающим членам общества. Важно отметить, что эти два принципа вовсе не тождественны справедливости. Понятие справедливости является более широким и, по интерпретации Ролза, скорее относится к психологической характеристике участников мысленного эксперимента.

Итак, каждый из принимающих данное решение индивидов:

(1) возможно не обладает некоторыми знаниями относительно добра и зла, но обладает свойством «быть моральной личностью»;

(2) в своем поведении руководствуется исключительно собственными интересами.

Это означает, что Ролз, вслед за Вебером, по существу использует 
предпосылку о субстанциальном характере для человеческого общества рациональности (конечно же, истолкованной определенным образом).

Однако, не только рациональная природа человека опосредует выбор двух вышеуказанных принципов. Главным обстоятельством все-таки является не отсутствие знания, например, о добре и зле, а скорее отсутствие знаний о своих преимуществах, правах, в соотношении с правами и преимуществами других индивидов. Иными словами, договариваться участникам будущего соглашения имеет смысл только в том случае, когда есть страх оказаться в проигрыше, когда «война всех против всех» непосредственно затрагивает личные интересы каждого из участников будущего договора. При этом, по мнению Ролза, все «договаривающиеся стороны» должны придерживаться логики, то есть быть последовательными при принятии и отстаивании своих решений.

Здесь уместно напомнить, что речь идет о договоре гипотетическом, в действительности никогда не существовавшем, поэтому совершенно неясно, почему нельзя в таком же гипотетическом ключе рассмотреть данную ситуацию с противоположной стороны, то есть, как развивающуюся вопреки логике. Для этого достаточно предположить, что рациональность субъекта, пусть даже и «ориентированная на другого» (Вебер) не всегда может иметь целью рациональность другого, хотя вполне может ее учитывать. Собственно, критики концепции Ролза неоднократно выражали сомнение относительно самой возможности консенсуса, достигнутого на основе такого понимания рационального субъекта, когда из-за неведения о своих «ресурсах и талантах» субъект не в состоянии «отстаивать принципы, которые существенно нечестны, так как благоприятствуют одним комбинациям ресурсов и таланта и не благоприятствуют другим» [1].

В качестве примера такого аргумента приведем хорошо известную «дилемму заключенного», которую для простоты сформулируем в терминах некой телеигры. Участники игры имеют на кону большую сумму денег, которую можно получить (или не получить) в соответствии со следующими правилами:

1. Если оба партнера согласны поделить выигрыш пополам, то сумма делится между ними.

2. Если один из игроков согласен делить выигрыш, а второй отказывается это делать, то всю сумму получает второй игрок.

3. Если оба участника не согласны делиться, то деньги не достаются никому из них. ${ }^{1}$

\footnotetext{
${ }^{1}$ Игра с такими правилами (под названием «Judas Game») шла на одном из телеканалов телевидения Германии в 2003-2004 гг.
} 
Данные условия можно представить посредством своеобразной «таблицы истинности»:

\begin{tabular}{|c|c||c|}
\hline$A$ & $B$ & Результат \\
\hline \hline да & да & выигрывают оба (50\%) \\
\hline нет & да & выигрывает «плохой» \\
\hline да & нет & выигрывает «плохой» \\
\hline нет & нет & проигрывают оба \\
\hline
\end{tabular}

Таким образом, мы абстрагируемся от психологических характеристик или моральных качеств героев игры, их коварства, благородства и т.п., что, конечно же, существенно для создателей шоу и телезрителей и составляет, вероятно, наиболее важную и захватывающую часть зрелища.

Теперь «подсчитаем», какой тип поведения приводит к большему успеху - компромиссный или эгоистичный. Несложный математический расчет показывает, что при заданных условиях, если я скажу нет, то могу выиграть все или проиграть все, если же я не буду «коварным эгоистом», то получу половину или проиграю. При сравнении «положительных» результатов (при наличии благоприятных условий), мы видим, что «праведное» поведение может дать самое большее половину суммы, «неправедное»- все. Если же рассмотреть эту ситуацию глазами стороннего наблюдателя (социолога), то оказывается, что совпадение «доброй воли» случается не так уж и часто - как несложно видеть соотношение здесь $1: 3$ и отнюдь не в пользу согласия и компромисса.

Данный пример призван продемонстрированть, что с точки зрения «рационального» субъекта, который давно, с легкой руки М. Вебера, стал основной действующей фигурой многих социологических и экономических теорий ${ }^{2}$, выбор «эгоистической» линии поведения становится, в силу своей эффективности, практически неизбежным.

Главная ошибка как Ролза, так и некоторых его критиков, по мнению Макинтаира, кроется в отсутсвии учета так называемых «заслуг в решении задач коммуны по преследованию общих благ» [2, с.340]. Этот упрек по существу обращает внимание на то обстоятельство, что у абстрактных рациональных индивидов, по-видимому, еще нет навыков социальной жизни и программы «выживания вместе», поэтому может показаться, что можно получить улучшенный вариант теории Ролза посредством улучшения ее исходных параметров. Однако, на наш взгляд, это также принципиально невозможно в силу следующих аргументов.

\footnotetext{
${ }^{2} \mathrm{~K}$ таким концепциям относятся, например, так называемые «теории рационального выбора», в которых «человеческие особи рассматриваются как „максимизаторы выгоды“, чьи действия ... нацелены на максимально возможное увеличение собственного благополучия» [5].
} 
В приведенном примере телеигры, где, кстати, участники имеют право предварительно договариваться между собой, что вызывает иллюзию возможности нахождения надежных «партнеров по бизнесу» и объединения усилий в совместном движении к общей цели, исход игры все-таки остается абсолютно неопределенным независимо от выбранной в идеальном случае солидаристской стратегии: мало кто в состоянии сохранить доверие к партнеру до конца. Другими словами, счет 1:3 в пользу «рациональности» указывает на изначальную бедность «исходной ситуации» в теории Ролза - участники договора делают выбор исходя из необходимости для данной теории именно данных выводов.

Теория равновесия Ролза призвана включить некую моральную концепцию в объяснение получения основополагающих принципов, обосновывающих новые стратегии в социально-политической идеологии рыночной системы распределения, стремящейся уменьшить число маргинальных членов социального сообщества. По словам Ролза, в этой части своей теоретической аргументации он использует деонтологическую концепцию морали И.Канта, однако, учение Канта о долге является скорее лишь фильтром для прохождения через конкурс под названием «моральная личность». В результате такой минимизации критериев отбора мы получаем только тех, кто, условно говоря, придя на выборы, скажет «да», то есть, выдаст необходимый результат. Представим себе ситуацию с ночным сторожем, который должен регулярно закрывать 20 дверей с одинаковым замком, при этом обязан использовать для каждой двери отдельный ключ. Как результат, ситуация договора становится просто излишней, а сам договор просто-напросто теряет всякую необходимость. Таким образом, Ролз задает условия своей игры в форме беспроигрышной лотереи, где все получают призы. Конечно, такая игра очень выгодна ее участникам, но вряд ли она будет выгодна организаторам.

Не вызывает сомнения тот факт, что указанные принципы являются критерием приверженности идеалам демократии в оценке деятельности правительств современных развитых государств, они же являются базовыми в формировании критики в адрес действующего правительства, или, скажем, идущей на выборы партии. Однако природа их не в том, что с ними согласны все «рациональные» члены сообщества и это виртуальное согласие предъявляется государству для исполнения; природа их, если аппелировать к общественному договору, по словам Макинтаира, состоит в том, что «в центре современной социальной структуры не консенсус, а конфликт» [2, с. 342].

Таким образом, приходим к выводу, что теория справедливости, способная служить в качестве основы функционирования социальных институтов и являться критерием «правильности» такого функционирования, не может быть логически выведена из ситуации общественного договора. 
Все конструкции в области социальных, экономических и политических теорий четко разделяют социальную и «моральную» теории справедливости. Последняя связывается с «чувством» справедливости, «интуитивным» восприятием справедливого и несправедливого и т.п. Соотношение объемов этих двух теорий может быть наглядно представлено в виде пересечения, где пересекающаяся область достаточно обширна и представлена целым рядом проблем. Однако при такой интерпретации довольно очевидно, что «общая часть» не является метатеорией и что «общая теория справедливости» если и возможна, то скорее как глобальная концепция, которая по своей природе должна иметь онтологический характер.

\section{1 Литература}

[1] Дворкин P. Справедливость и права // Отечественные записки, 2003. 一№ 2 .

[2] Макинтаир A. После добродетели: исследования теории морали.М.: Академический Проект; Екатеринбург: Деловая книга, 2000.

[3] Ролз Дж. Теория справедливости.-Новосибирск, 1995.

[4] Роулс Д. Теория справедливости (Фрагменты из книги) // Этическая мысль: Научно-публицистические чтения / Редкол.: А.А. Гусейнов и др. - М.: Политиздат, 1990.- С. 229-242.

[5] Фармер M. Рациональный выбор: теория и практика // Полис, 1994. - № 3 .

[6] Kukathas C., Pettit P. Rawls. A Theory of Justice and its Critics. Stanford, 1990. 